\title{
Ortam Sesinden İnsan Sesinin Ayrıştırılması için Filtre Geliştirilmesi
}

\author{
Süleyman Çeven ${ }^{1}$, Raif Bayır ${ }^{2 *}$ \\ ${ }^{1}$ Düzce Üniversitesi, Düzce Meslek Yüksekokulu, Elektronik ve Otomasyon Teknolojisi Bölümü, Düzce, Türkiye (ORCID: 0000-0002-8970-4826) \\ ${ }^{2}$ Karabük Üniversitesi, Teknoloji Fakültesi, Mekatronik Mühendisliği Bölümü, Karabük, Türkiye (ORCID: 0000-0003-3155-8771)
}

(Bu yayın 26-27 Haziran 2020 tarihinde HORA-2020 kongresinde sözlü olarak sunulmuştur.)

(DOI: $10.31590 /$ ejosat.780074)

\begin{abstract}
ATIF/REFERENCE: Çeven, S., \& Bayır, R. (2020). Ortam Sesinden İnsan Sesinin Ayrıştırılması için Filtre Geliştirilmesi Avrupa Bilim ve Teknoloji Dergisi, (Special Issue), 331-337.

$\ddot{O} \mathbf{z}$

Bu çalışmada, endüstri ortamında talaşlı imalat yapan bir üretim tesisinde, torna operatörü olarak görev yapan bir insanın ses sinyallerinin, istenmeyen dış ortam kaynaklı seslerin filtrelenmesiyle ortaya çıkarılması ve operatör konuşma ses sinyallerinin netleştirilmesi sağlanmıştır. Çalışmada bir insanın konuşmasına ait ses sinyalleri mikrofon yardımıyla kaydedilmiş, kaydedilen konuşma ses sinyalleri üzerine Matlab ortamında torna sesinin ve ortam ses sinyallerinin benzetimi yapılarak eklenmiştir. Benzetimi yapılan gürültülü ses sinyalinde FFT işlemi yapılarak, operatör sesi ve diğer ortam seslerinin frekans spektrumları gözlenmiştir. Benzetimi yapılan ses sinyalinde dış ortam kaynaklı ses sinyallerinin frekans dalga boyları tespit edilmiş̧ir. Gürültülü ses sinyalinden FIR band engelleyen filtre ve alçak geçiren filtre kullanılarak dış ortam sesleri filtrelenmiş ve operatör sesi net bir şekilde elde edilmiştir.
\end{abstract}

Anahtar Kelimeler: Sinyal işleme, Fast fourier transform, Finite impulse response filtreler.

\section{Developing Filter to Separate Human Voice from Ambient Sound}

\begin{abstract}
In this study, it is aimed to reveal the sound signals of the lathe operator by filtering them from outside sounds and clarify the sound signals in a production plant that produces machining in the industrial environment. In the study, the audio signals of the speech of the lathe operator were recorded with the help of a microphone. On the recorded speech audio signals, lathe and ambient audio signals were created in Matlab environment and added. In Matlab environment, noisy sound signal simulation that includes operator and environment sounds is made. FFT operation was performed on the noisy sound signal and frequency spectra of operator sound and other ambient sounds were observed. Frequency wavelengths of noisy signals were determined in the simulated audio signal. Outside sounds are filtered using the FIR band stop filter and low pass filter from the noisy sound signal and the operator sound is obtained clearly.
\end{abstract}

Keywords: Signal processing, Fast fourier transform, Finite impulse response filters.

\section{Giris}

Akustik, ses sinyallerini inceleyen bir bilim dalıdır (Rezaei and Salehi 2006). İnsan seslerinin analiz edilmesinin yanı sıra hemen her ses sinyali bu alanda değerlendirilmekte ve bu sinyallerin analizi akustik bilim dalı altında yapılmaktadır (Ma et al. 2020). Ses analizleri ses bozuklularının değerlendirilmesinde, sinyallerin iyileştirilmesinde kullanılmaktadır (Dyer and Harms 1993). Bu işlemlerde kullanılan temel parametreler, perde, jitter ve shimmer olarak literatürde yerini almıştır (Fannin et al. 1991). Perde, ses sinyalinde oluşan kıvrımların saniyede oluşturduğu açılma-kapanma durumudur. Sesin kalınlık ve inceliğinin tanımlanmasında kullanılmaktadır. Elektronikte bu parametreye sinyal frekansı adı verilmektedir (Rezaei and Salehi 2006). Jitter sesin periyotlar arasındaki değişikliği gösteren parametredir. Shimmer ise sinyal genliğindeki periyodik değişimlere verilen addır (Dyer and Harms 1993). Günümüzde ses sinyalleri çeşitli sensör teknolojileri kullanılarak elektrik sinyallerine dönüştürülmektedir. Ses dalgalarından elde edilen elektrik sinyalleri işlenerek farklı uygulamalarda farklı amaçlar için kullanılmaktadır (Dyer and Harms 1993). Sesten elde edilen elektrik sinyalleri, ADC ile sayısal sistemlere aktarılabilir, bu sistemlerde işlenebilir ve DAC ile analog sistemlere aktarılabilmektedir (Moseiko et al. 2020).

\footnotetext{
${ }^{*}$ Sorumlu Yazar: Corresponding Author: Karabük Üniversitesi, Teknoloji Fakültesi, Mekatronik Mühendisliği Bölümü, Karabük, Türkiye, ORCID: 0000-0003-3155-8771, rbayir@karabuk.edu.tr
} 
Sinyal işleme (SP- Signal Processing) yöntemleri mühendislik biliminde yaygın olarak kullanılan başarılı bir yöntemdir ve elektrik sinyalinin sayısal yöntemlerle işlenmesi ile ilgilenmektedir (Marciniak et al. 2019). Sayısal sinyal işleme yöntemleri kullanılarak ses sinyalinin güçlendirilmesi, istenilmeyen frekansa sahip sinyallerin bastırılması, belirli aralıktaki frekansa sahip sinyallerin geçirilmesi gibi işlemler yapılmaktadır (Fannin et al. 1991). Ses sinyallerinde filtreleme olarak tabir edilen işlemler sayesinde ses sinyali üzerinde değişiklikler yapılmasına olanak sağlanmaktadır (Raz, Marketing, and Borth 1986). Filtreleme işlemi günümüzde filtre adı verilen sistemler sayesinde yapılmaktadır (Chen, Wang, and Wang 2014). He ve diğ. Konuşma sesinden karakteristik özellikleri çıkartmak için iki yeni yöntem önermişlerdir. Kullanılan yöntemlerde $12 \log$-Gabor filtreleri kullanmıştır. Çalışma sonucunda \%40-\%81 arasında değişen doğrulukta sınıflandırma elde etmişlerdir (He et al. 2009).

MacCallum ve diğ. alçak geçiren filtrenin kesim frekansının ses analizi üzerinde etkilerini araştırmış ve en uygun kesim frekansının $300 \mathrm{~Hz}$ olduğunu öne sürmüşlerdir (MacCallum et al. 2011). Chen ve diğ. $5 \mathrm{~dB}$ sinyal gürültü oranı seviyesinden daha düşük 6 farklı gürültü kullanarak ses sinyalinde sınıflandırma doğruluğunu artırmak için yeni bir yöntem kümesi sunmuştur. Sonuçlar elde edilen yöntem kümesinin sınıflandırmada yüksek doğruluk ürettiğini göstermiştir (Chen, Wang, and Wang 2014). Siegert ve diğ. konuşma ses sinyallerinde görünmeyen spektral değişimleri temizlemek ve çevresel gürültüleri filtrelemek için Bağıl Spektral (RASTA-Relative Spectral) filtre ve Cepstral Ortalama Çıkarım (CMS-Cepstral Mean Subtraction) yöntemlerini kullanmıştır (Siegert et al. 2014). Başka bir çalışmada akustik olay sınıflandırıcı için iki yeni öneri sunulmaktadır. Önerilerden birinde farklı akustik sinyallerin spektral karakteristikleri incelenmiş ve ikinci öneride yüksek geçiren filtre tabanlı yeni bir filtre yapısı ortaya atılmıştır. Sonuçlar filtrelenmiş ses sinyalinde iyileşme olduğunu göstermiştir (Ludeña-Choez and Gallardo-Antolín 2015). Bu çalışmada alçak geçiren ve band engelleyen FIR filtreler kullanılarak operatör sesi, dış ortam seslerinden ayrılarak işlenmiş ve sonuçlar karşılaştırılmıştır. Çalışmanın ikinci bölümünde materyal ve metod, üçüncü bölümünde deneysel çalışmalar, dördüncü bölümde ise sonuçlar değerlendirilmiştir.

\section{Materyal ve Metot}

\subsection{Filtreler}

Filtreler, mekanik uygulamalarda istenmeyen özelliklere ve parametre değerlerine sahip etkenlerin, uygulamada kullanılan elemanlara zarar vermemesi için, elektrik-elektronik uygulamalarda ise belirli dalga boyuna ve frekansa sahip elektrik sinyallerinin iletilmesi, diğer sinyallerin ise elektriksel geçirgenliğinin engellenmesi işlemlerinde kullanılmaktadır (Damera, Karşılayan, and SilvaMartinez 2016; Miki and Rakers 2004; Okoniewski and Piskorowski 2019). Elektronik filtreler temelde analog filtreler ve dijital filtreler olmak üzere ikiye ayrılırlar (Thede 2005; Wanhammar 2009). Analog filtreler istenmeyen frekans aralığında bulunan elektrik sinyallerin geçişinin engellenmesinde yani susturulmasında kullanılmaktadır. Burada, analog filtreler kullanım amaçları veya gereksinimlere göre aktif ya da pasif filtre olarak adlandırılan topolojiler kullanılarak tasarlanabilmektedir (Okoniewski and Piskorowski 2019; Thede 2005; Vural et al. 2012). Analog filtreler genel olarak yapılarında elektriksel direnç, kapasite elemanı, indüktör elemanı ve işlemsel yükselteç devre elemanları barındırmaktadır (Grebenko et al. 2019; Hameed and Pamarti 2018; Maheshwari 2018; Mondal and Krishnapura 2018). Dijital filtreler bilgisayar ve özel amaçlı donanımlar kullanılarak gerçekleştirilebilmektedir. Dijital filtreler genel olarak bir işlem sürecinde, çeşitli algoritma ve yazılım yöntemleri kullanılarak giriş sinyali olarak adlandırılan sayı dizisini istenilen çıkış sinyali sayı dizisine çevrilmesi işlemine verilen addır. Böylelikle analog filtrelerde olduğu gibi istenmeyen frekans aralığında bulunan sinyallerin engellenmesi sağlanmaktadır (Marciniak et al. 2019; Miki and Rakers 2004; Thede 2005; Wanhammar 2009). Analog filtreler başlığı altındaki aktif filtrelerde elektriksel direnç, indüktör ve kapasite elemanı yanı sıra işlemsel bir yükselteçten üretilen harici bir enerji kaynağı kullanılmaktadır (Afacan et al. 2015; D’Amico et al. 2019; Gaunholt 2007). Pasif filtreler ise sadece elektriksel direnç, indüktör ve kapasite elemanından oluşmaktadır (Miki and Rakers 2004). İsteğe bağlı olarak pahalı ve boyut olarak avantaj sağlamadıkları gerekçesiyle indüktör elemanı bu tip filtre devrelerinde tercih edilmemektedir.

Günümüzde filtreler frekans geçişlerine göre sınıflandırılmaktadır. Alçak geçiren (LP-Low Pass) filtreler, sinyalin düşük frekanslarında geçişe izin veren yüksek frekanslarda geçişini engelleyen filtrelerdir. Yüksek geçiren (HP-high pass) filtreler, alçak geçiren filtrelerin tersine sinyalin yüksek frekanslarda geçişine izin veren, düşük frekanslarda geçişini engelleyen filtrelerdir. Bant durduran (BS-band stop) filtreler, belirlenen alt ve üst kesim noktaları arasında sinyalin geçişini engelleyen filtrelerdir (Gaunholt 2007). Filtrelerin sınıflandırılmasına ait görsel Şekil 1'de verilmektedir. Filtreler ses sinyallerinin işlenmesinde ve sayısal olarak değerlendirilmesinde yaygın olarak kullanılan sayısal sinyal işleme yöntemlerinin temelini oluşturmaktadır.

Genel olarak bir elektrik sinyali farklı frekans aralığında farklı genlikteki sinyallerin üst üste toplanmasından oluşmaktadır. Filtreler sayesinde belirli bir frekans aralığında ve genliğinde olan sinyal, toplam sinyalden ayıklanabilmekte ve rahatlıkla işlenebilmektedir. Filtreye bir giriş sinyali uygulanırsa örneğin $\mathrm{x}(\mathrm{t})$, filtrenin çıkışı $\mathrm{y}(\mathrm{t})$ sinyali olacaktır. Örnek olarak bir AM (Amplitude Modulated) sinyali düşünülüp, bu sinyalin $\mathrm{N}$ farklı sinyalden oluştuğu ve bu sinyallerin tamamının genliklerinin (Ai), modülasyon katsayılarının $(\mu \mathrm{i})$, sinyallerin (fi) ve iletim frekanslarının ( $\omega$ i) farklı olduğu düşünülürse giriş sinyali matematiksel ifadesi Eşitlik 1 gibi olacaktır.

$$
\begin{aligned}
& x(t)=\sum_{i=1}^{N} A_{i}\left[1+\mu_{i} f_{i}(t)\right] \cos \left(\omega_{i} t\right) \\
& y(t)=A_{3}\left[1+\mu_{3} f_{3}(t)\right] \cos \left(\omega_{3} t\right)
\end{aligned}
$$

Eşitlik 1'de verilen giriş sinyalinde ayıklanması istenen $\mathrm{N}=3$ numaralı sinyal olması gerektiği düşünüldüğünde $y(t)$ 'nin Eşitlik 2'deki gibi olması gerekmektedir. 


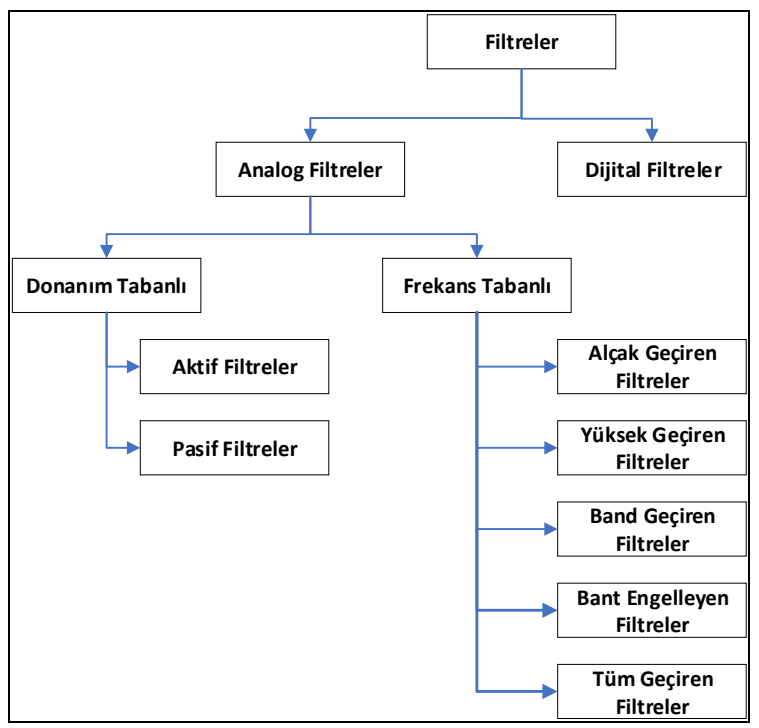

Şekil 1. Filtrelerin sınıflandırılması

Şekil 2'de temel bir filtrenin çalışmasına ait blok diyagramı verilmektedir. Bir ideal alçak geçiren filtre çalışma prensibine ait matematiksel ifade Eşitlik 3 'te verilmektedir. Burada $\omega_{c}$ ideal alçak geçiren filtrenin kesme frekans değeri, $\omega$ filtre giriş sinyali frekans değeri, $H_{L P}(j \omega)$ ise filtre cevabı olarak verilmektedir. Bir ideal band engelleyen filtre çalışma prensibine ait matematiksel ifade Eşitlik 4 'te verilmektedir.

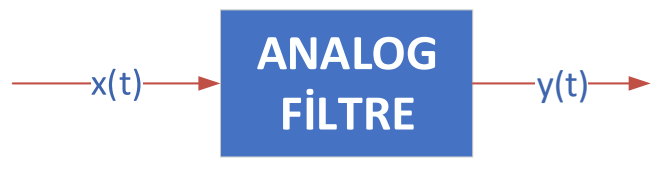

Şekil 2. Temel filtre çalışma blok diyagramı.

Pencere fonksiyonları, sonlu impuls cevaplı (FIR, Finite Impulse Response) sayısal filtre tasarımında istenmeyen salınımları ortadan kaldırmak için kullanılan fonksiyonlardır (Avcı and Gümüşsoy 2020). Çalışmada istenmeyen ortam seslerini gürültülü benzetim ses sinyalinden ayırmak için band engelleyen ve alçak geçiren filtreler ses sinyaline uygulanmıştır. Burada Kaiser penceresi kullanılmış ve filtreler üzerinde tercih edilmiştir. Ayarlanabilir parametre özelliği ile sayısal filtrelemede yaygın olarak tercih edilen Kaiser penceresi Eşitlik 5'teki gibi tanımlanabilir.

$\left|H_{L P}(j \omega)\right|=\left\{\begin{array}{ll}1, & |\omega|<\omega_{c} \\ 0, & |\omega|>\omega_{c}\end{array}\right\}$

$\left|H_{B P}(j \omega)\right|=\left\{\begin{array}{c}0, \quad \omega_{2}>|\omega|>\omega_{1} \\ 1, \quad \omega_{2}<|\omega|,|\omega|<\omega_{1}\end{array}\right\}$

$w_{k}(n)=\left\{\begin{array}{cl}\frac{I_{0}\left(a_{k} \sqrt{1-\left(\frac{2 n}{N-1}\right)^{2}}\right)}{I_{0}\left(a_{k}\right)}, & |n| \leq \frac{N-1}{2} \\ 0 \quad, \text { diğer yerlerde }\end{array}\right.$

Eşitlik 5 'te $a_{k}$ ayarlanabilir ayarlama değeri ve $I_{0}(x)$ sıfirıncı dereceden geliştirilmiş Bessel fonksiyonudur. Bessel fonksiyonun güç serisi açılımı Eşitlik 6'da verilmektedir.

$I_{0}(x)=1+\sum_{k=1}^{\infty}\left[\frac{1}{k !}\left(\frac{x}{2}\right)^{k}\right]^{2}$

Sabit pencere için N'in arttırılması analob genişliği arttırırken, dalgalanma oranı sabit kalmaktadır. Ancak Kaiser penceresinde $a_{k}$ ayarlama parametresi arttıkça analob genişlikte artışa dalgalanmada ise azalmaya neden olmaktadır. Şekil 3'te ayarlama parametresindeki değişimin pencere üzerinde etkileri verilmektedir. 


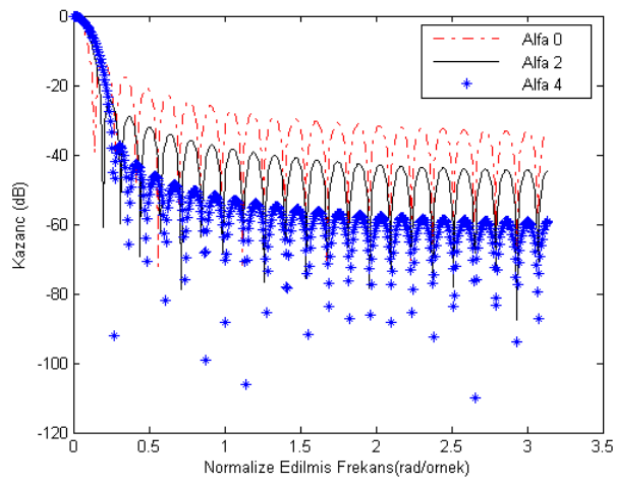

Şekil 3. Farklı ayarlama parametrelerinde Kaiser penceresi.

Çalışmada kullanılan Kaiser penceresinde ayarlama parametresi "2" olarak seçilmiştir. Pencere maksimum sapmaları ise "0.01" ve " 0.05 ” olarak seçilmiştir. Pencere örnekleme frekansı ise ses sinyali frekansı olan $22.05 \mathrm{kHz}$ olarak belirlenmiştir. Çalışmada Kaiser penceresi ile LP ve BP filtreleri tasarlanmıştır. Benzetim çalışmaları Matlab ortamında yapılan ses sinyalindeki ortam gürültülerine ait frekans spektrumları göz önünde bulundurularak tasarlanan filtrelere ait parametreler Tablo 1'de verilmektedir.

Tablo 1. Kullanılan filtrelere ait özellikler

\begin{tabular}{l|c|c|c}
\hline Filtre türü & $\mathbf{f}_{\mathbf{1}}$ & $\mathbf{f}_{\mathbf{2}}$ & $\mathbf{w}$ \\
\hline Alçak geçiren filtre & 900 & 2250 & 100 \\
\hline Bant durduran filtre & 250 & 350 & 25 \\
\hline
\end{tabular}

\subsection{Fast Fourier Dönüşümü}

Fourier dönüşümü temel olarak $\mathrm{N}$ adet kompleks $\mathrm{x}(\mathrm{n})$ veri kümesini $\mathrm{N}$ adet $\mathrm{X}(\mathrm{k})$ kümesine Eşitlik (7) ile çevirmektedir (Li et al. 2020). Burada faz faktörü $\mathrm{W}_{\mathrm{N}}$ Eşitlik (8) ile ifade edilmektedir.

$$
\begin{aligned}
& X(k)=\sum_{n=0}^{N-1} x(n) W_{N}^{k n}, 0 \leq k \leq N-1 \\
& W_{N}=e^{-j 2 \pi / N}
\end{aligned}
$$

Eşitlik (7)'den görüldüğü üzere her "k" değerini hesaplamak için "N" sayıda çarpma ve "N-1" sayıda toplama yapılmaktadır. Ek olarak, " $\mathrm{N}$ " sayıda " $\mathrm{k}$ " değerini hesaplamak için " $\mathrm{N}$ " sayıda çarpma ve "N2$-\mathrm{N}$ " sayıda toplama yapılmaktadır. Hesaplanan sonuçların kaydedilmesi için "2N" sayıda hafızaya gerek duyulmaktadır.

Fourier dönüşümünde faz faktöründe simetri ve tekrarlama özellikleri bulunmadığından hesaplama hızı yavaş ve performansı düşüktür. Literatürde Radix vektörleri ve çeşitli algoritmaların kullanımı ile faz faktöründe bu özellikler kullanılarak hesap miktarı azaltılmakta ve işlem hızlandırılmaktadır. Bu algoritmalardan en yaygın kullanılanı Radix-2 algoritmasıdır. Radix-2 ile Fourier dönüşümü parçalama ve hesaplama ile birbirini tekrar eden işlemlere indirgenmektedir. Böylece FFT (Fast Fourier Transform) için gereken çarpma sayısı "(N/2) $\log 2(\mathrm{~N})$ "' sayıda işleme indirgenmektedir. Toplama ise "Nlog2N" sayıda olmaktadır. Buna karşlılı hafiza boyutu Fourier dönüşümündeki gibi aynı sayıda olmaktadır.

Parçalama ve hesaplama ile parçalama işlemi iki farklı şekilde yapılmaktadır. İlk yaklaşımda giriş veri dizisi tek indeks ve çift indeks değerleri olarak ayrılmakta ve bu şekilde hesaplanmaktadır. Bu yönteme zaman üzerinde seyrekleştirmeli FFT adı verilmektedir. İkinci yaklaşımda ise giriş veri dizisi ortadan ikiyi ayrılarak hesaplama işlemi yapılmaktadır. Bu yönteme ise frekans üzerinde seyrekleştirmeli FFT adı verilmektedir. İki yaklaşım da eşdeğer işlevi görmektedir. Çarpma, toplama işlem sayıları ve gerekli hafıza boyutu farklılık göstermemektedir. Çalışmada ses sinyallerinin FFT analizleri Matlab ortamında gerçekleştirilmiştir.

\section{Deneysel Çalışmalar}

Çalışmada operatör ses sinyallerine Matlab ortamında oluşturulmuş farklı frekanslarda eşit genliklerde gürültü sinyalleri oluşturulmuş ve bu sinyallerin toplanmasıyla ortam gürültü sinyali elde edilmiştir. Şekil 4 'te farklı gürültü sinyalleri ve toplam ortam gürültü sinyali verilmektedir. Gürültü sesleri ile operatör sesi toplanarak talaşlı imalat ortamı benzetimi gerçekleştirilmektedir. Üç farklı frekansta gürültü sinyalinin oluşturulmasındaki temel neden insan konuşma sesi frekans sınırlarının 0 ile $800 \mathrm{~Hz}$ aralığında olmasıdır. Böylece kullanılan filtrenin performansı rahatlkla analiz edilmektedir. 


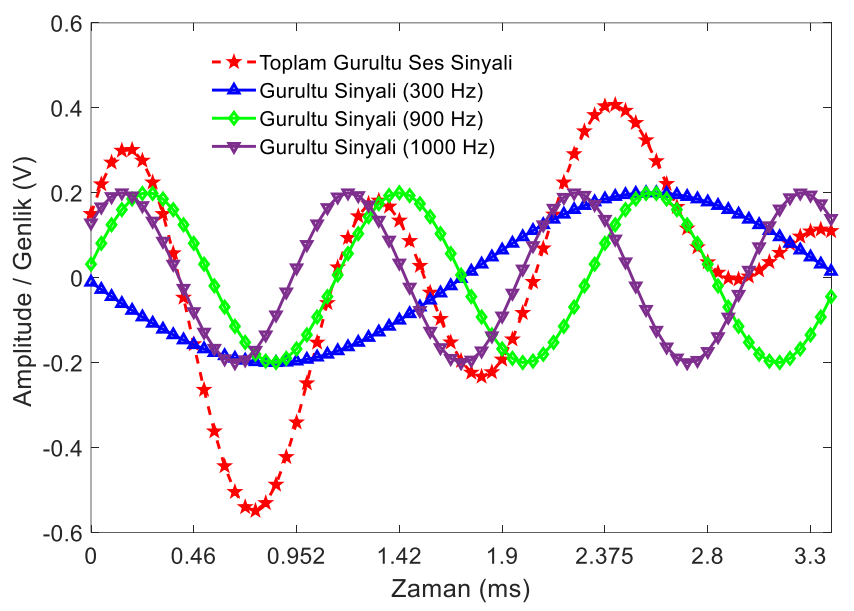

Şekil 4. Gürültü sinyalleri

Operatörün ses sinyallerine ait grafik Şekil 5(a)'da verilmektedir. Operatörün konuşma süresi yaklaşık olarak 5 saniyede sınırlandırılmıştır. Ortam gürültü frekansları değerlendirildiğinde bu zaman dilimin yeterli olduğu düşünülmektedir. Operatör ses sinyalleri ve oluşturulmuş ortam gürültü sinyallerinin toplamından filtre uygulanacak benzetim sinyali elde edilmektedir. Benzetim sinyali Şekil 5(b)'de verilmektedir. Benzetim sinyali ile operatör ses sinyallerinin kıyaslanması için Şekil 5(a)'da verilen operatör ses sinyallerine Matlab ortamında FFT uygulanmıştır. FFT alınmış sinyal Şekil 5(c)'de verilmektedir.

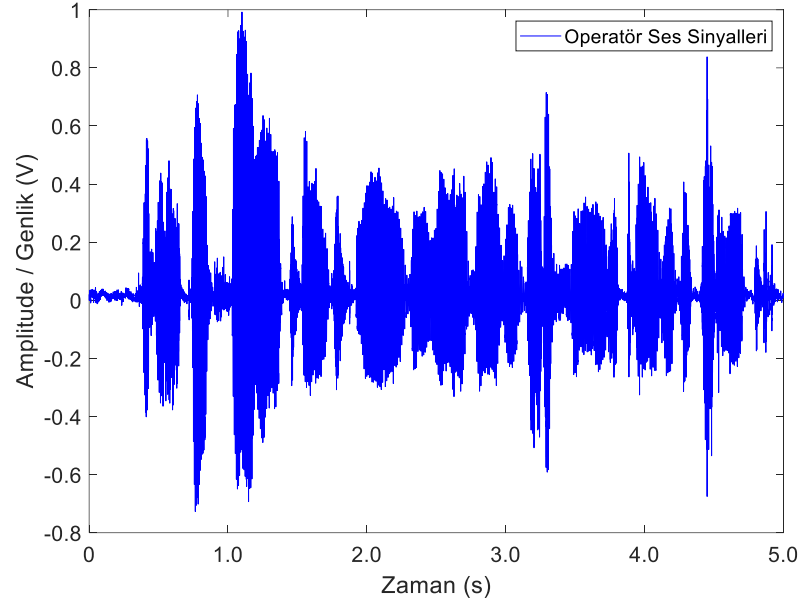

(a)

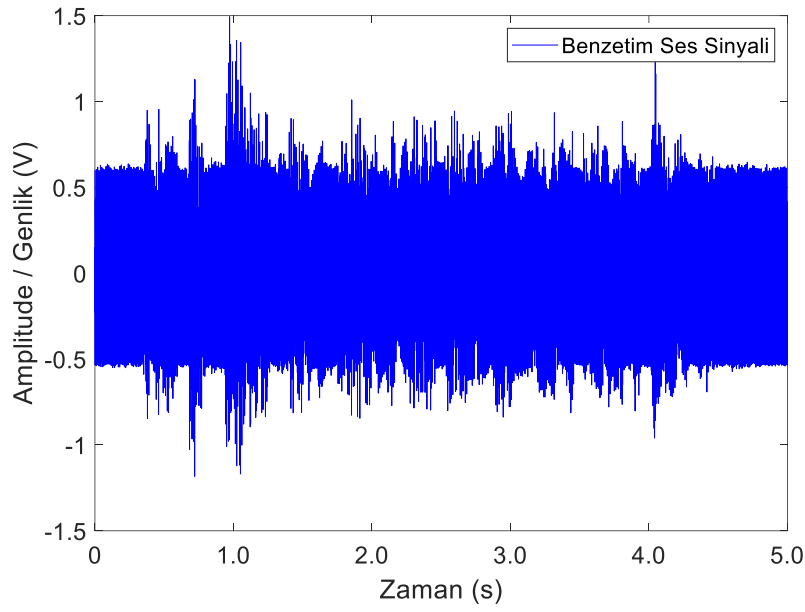

(b)

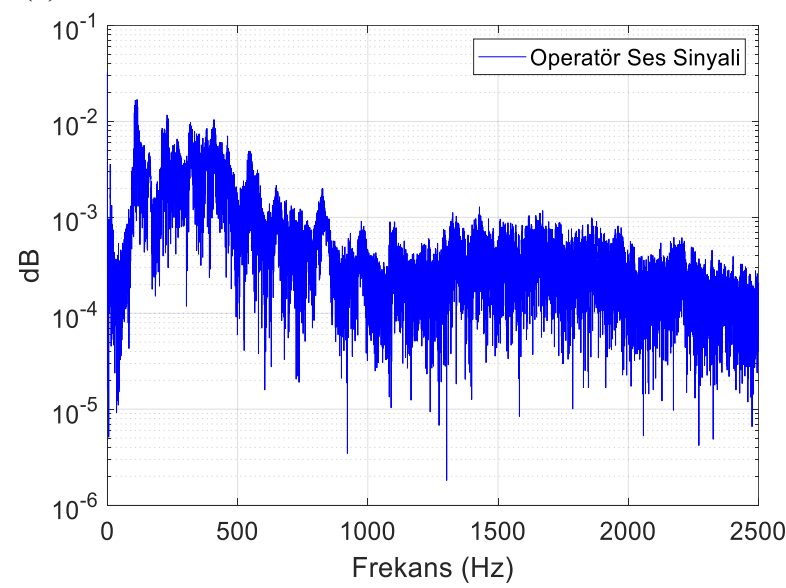

(c)

Şekil 5. (a)Operatör ses sinyali, (b)Benzetim ses sinyali, (c)Operatör ses sinyali FFT spektrum grafiği

Benzetim ses sinyali üzerinde ortam gürültü ses sinyallerini tespit etmek ve operatör ses sinyali ile karşılaştırmak için Matlab ortamında sinyale FFT uygulanmıştır. FFT alınmış sinyal Şekil 6(a)'da verilmektedir. Şekil 5(c) ve Şekil 6(a)'da verilen FFT uygulanmış ses sinyalleri incelendiğinde ortam gürültüsü sinyallerine ait frekans spektrumları rahatlıkla tespit edilebilmektedir. Burada $300 \mathrm{~Hz}, 900$ $\mathrm{Hz}$ ve $1000 \mathrm{~Hz}$ frekans değerine sahip üç sinyalin gürültü oluşturduğu görülmektedir. Gürülttü ses sinyallerinin sahip olduğu frekans band aralıklarında gerekli filtreler uygulanmasıyla operatör ses sinyali süzülerek elde edilecektir. Kaiser çerçevesi kullanılarak tasarlanan alçak geçiren filtre ve band engelleyen filtreler benzetim sinyaline uygulanarak operatör ses sinyali elde edilmektedir. 


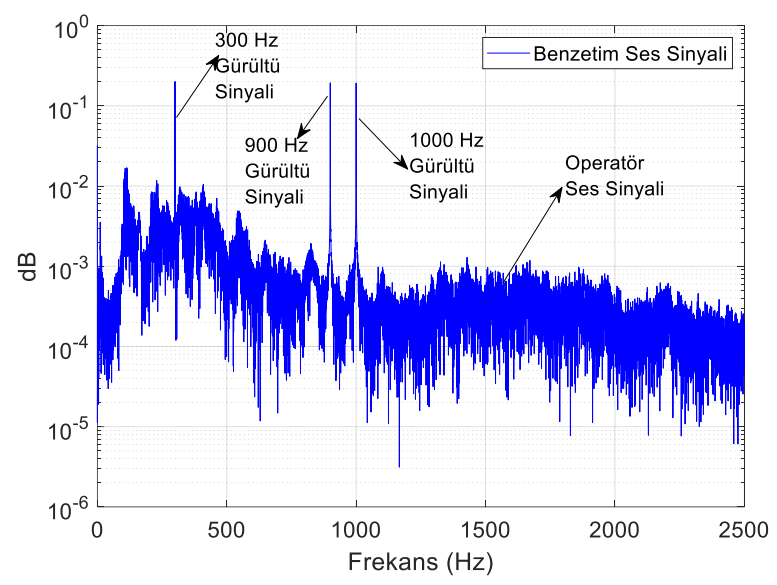

(a)

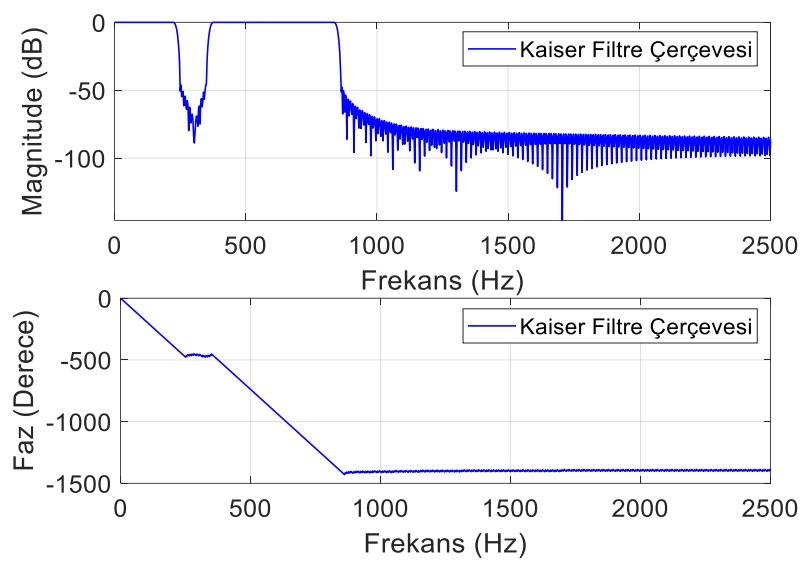

(b)

Şekil 6. (a)Benzetim sinyali FFT spektrum grafiği, (b) Tasarlanan filtre frekans geçiş ve faz geçiş grafiği.

İnsan sesi 0-800 Hz frekans bandında değişken spektral özellikler gösterdiğinden burada alçak geçiren filtre ile birlikte band engelleyen filtre kullanılması kaçınılmaz bir durum oluşturmaktadır. Matlab ortamında tasarlanan filtrelerin frekans geçiş grafiği ve faz geçiş grafiği Şekil 6(b)'de verilmektedir. Filtrelerin tasarımı Tablo 1'de verilen filtre özellikleri referans alınarak gerçekleştirilmiştir.

Benzetim ses sinyalinden filtrelenmesi amaçlanan ortam gürültü ses sinyallerinin başarı ile filtrelenebileceği Şekil 6(b)'da verilen filtre frekans geçiş grafiği incelendiğinde anlaşılmaktadır. Burada sinyalin $225 \mathrm{~Hz}$ ile $375 \mathrm{~Hz}$ frekans aralığındaki frekans bandının engellendiği, $800 \mathrm{~Hz}$ frekans aralığından daha büyük frekans değerlerine sahip sinyallerin ise filtreleneceği görülmektedir.

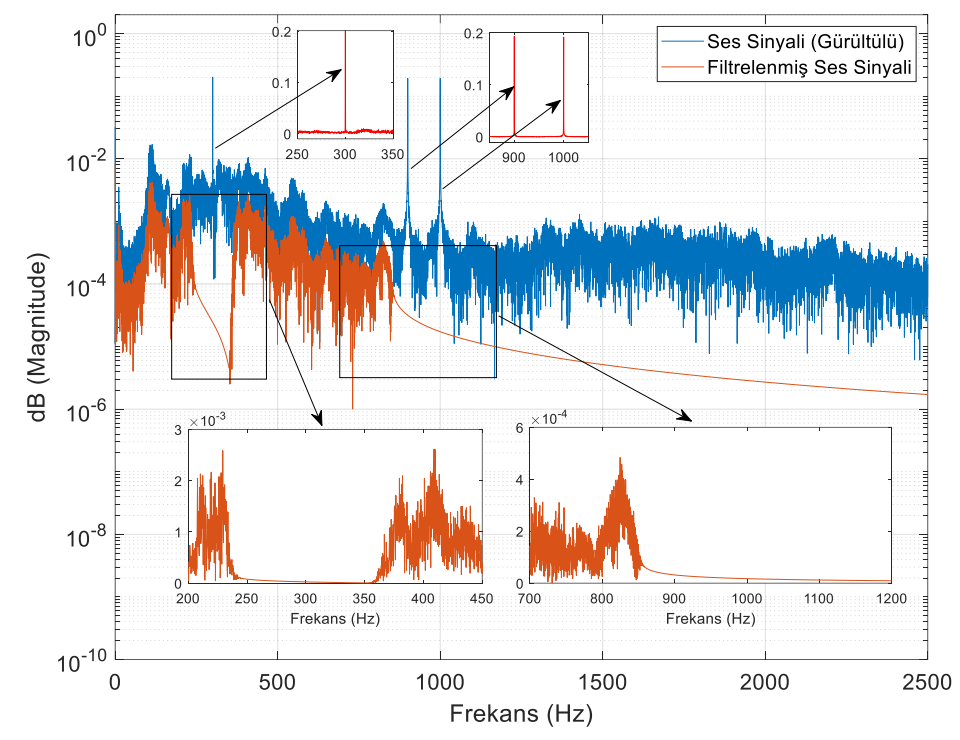

Şekil 7. Filtre çıkışı ve benzetim sinyali frekans geçiş grafiği

Kaiser çerçevesi referans alınarak tasarlanan FIR filtreler benzetim sinyaline uygulanmış ve sonuçlar analiz edilmiştir. Ayrıca Matlab ortamında oluşturulan ses sinyalleri .wav dosya uzantılı olarak kaydedilmiş ve operatörün orijinal konuşması, benzetim ses sinyali ve filtrelenmiş ses sinyalleri dinlenmiştir. Sonuç olarak gerçekleştirilen filtrelerin başarılı bir şekilde çalıştı̆̆ operatör sesinin başarıyla elde edildiği tespit edilmiştir. Benzetim ses sinyali ve filtre çıkış sinyallerinin frekans geçiş grafikleri Şekil 6(b)'de verilmektedir. Şekil 6(b)'de görüldüğü üzere tasarlanan FIR filtreler belirtilen frekans kesme bandında devreye girerek filtreleme işlemi gerçekleştirmektedir. Band engelleyen filtrenin benzetim sinyalini $225 \mathrm{~Hz}$ ile $375 \mathrm{~Hz}$ aralığında kestiğini, alçak geçiren filtrenin ise 800 Hz ve üstü frekansa sahip sinyalleri susturmaktadır.

\section{Sonuç}

Bu çalışmada, endüstri ortamında bulunan ve yoğun gürültü altındaki bir insanın konuşma ses sinyalleri ortam gürültüsünden arındırılarak filtrelenmektedir. Gürültü olmayan ortamda kaydedilen operatör konuşma sinyali ve gürültülü ortam benzetimi yapılarak kaydedilen ses sinyallerinin analizleri FFT kullanılarak yapılmıştır. Çalışma sonucunda FFT analizinin farklı frekans dalga boylarına sahip sinyallerin analiz edilmesinde oldukça başarılı bir yöntem olduğu görülmüştür. Çalışmada Kaiser çerçevesi referans alınarak FIR filtreler tasarlanmıştır. Gelecek çalışmalarda Kaiser çerçevesi ayarlama parametreleri değiştirilerek aynı filtreleme işleminin performansı değerlendirilecektir. Ayrıca Hamming, Blackman gibi farklı çerçeve modelleri de çalışmaya entegre edilerek filtre performanslarına olan etkileri karşılaştırmalı olarak yorumlanacaktır. 


\section{Kaynakça}

Afacan, Engin et al. 2015. "A Hybrid Quasi Monte Carlo Method for Yield Aware Analog Circuit Sizing Tool." Proceedings -Design, Automation and Test in Europe, DATE 2015-April: 1225-28.

Avc1, Kemal, and Eda Gümüşsoy. 2020. "Design, Analysis, and ECG Subband Processing Application of New M-Channel Cosine Modulated Uniform Filter Banks Based on Exponential Window Family." Journal of the Faculty of Engineering and Architecture of Gazi University 35(1): 193-211.

Chen, Jitong, Yuxuan Wang, and Deliang Wang. 2014. “A Feature Study for Classification-Based Speech Separation at Low Signal-toNoise Ratios." IEEE/ACM Transactions on Audio Speech and Language Processing 22(12): 1993-2002.

D’Amico, Stefano, Marcello De Matteis, Andrea Donno, and Andrea Baschirotto. 2019. “A 0.9 V 3rd-Order Single-Opamp Analog Filter in 28 Nm Bulk-CMOS.” Analog Integrated Circuits and Signal Processing 98(1): 155-67. https://doi.org/10.1007/s10470018-1261-y.

Damera, Saiteja, Aydın İlker Karşılayan, and Jose Silva-Martinez. 2016. "Design of Minimally Invasive All-Pole Analog Lowpass Filters." Analog Integrated Circuits and Signal Processing 88(2): 267-77.

Dyer, Stephen A., and Brian K. Harms. 1993. 37 Advances in Computers Digital Signal Processing.

Fannin, P. C., A. Molina, S. S. Swords, and P. J. Cullen. 1991. "Digital Signal Processing Techniques Applied to Mobile Radio Channel Sounding." IEE Proceedings, Part F: Radar and Signal Processing 138(5): 502-8.

Gaunholt, H. 2007. “A Numerical Design Approach for Single Amplifier, Active-RC Butterworth Filter of Order 5.” Proceedings - IEEE International Symposium on Circuits and Systems: 1927-30.

Grebenko, Yu A., R. I. Polyak, A. I. Starikovskii, and G. V. Kulikov. 2019. "Digital Methods for Linearization of Phase-Frequency Characteristics of Analog Filters." Journal of Communications Technology and Electronics 64(2): 126-32.

Hameed, Sameed, and Sudhakar Pamarti. 2018. "Design and Analysis of a Programmable Receiver Front End with Time-Interleaved Baseband Analog-FIR Filtering.” IEEE Journal of Solid-State Circuits 53(11): 3197-3207.

He, Ling, Margaret Lech, Namunu Maddage, and Nicholas Allen. 2009. "Stress and Emotion Recognition Using Log-Gabor Filter Analysis of Speech Spectrograms." Proceedings - 2009 3rd International Conference on Affective Computing and Intelligent Interaction and Workshops, ACII 2009: 1-6.

Li, Zhuyan et al. 2020. "Determining Dendrite Arm Spacing in Directional Solidification Using a Fast Fourier Transform Method." Computational Materials Science 173(August 2019): 109463. https://doi.org/10.1016/j.commatsci.2019.109463.

Ludeña-Choez, Jimmy, and Ascensión Gallardo-Antolín. 2015. "Feature Extraction Based on the High-Pass Filtering of Audio Signals for Acoustic Event Classification.” Computer Speech and Language 30(1): 32-42.

Ma, Jingwen, Ziyao Feng, Yuan Li, and Xiankai Sun. 2020. "Optically Controlled Topologically Protected Acoustic Wave Amplification.” IEEE Journal of Selected Topics in Quantum Electronics 26(5).

MacCallum, Julia K., Aleksandra E. Olszewski, Yu Zhang, and Jack J. Jiang. 2011. "Effects of Low-Pass Filtering on Acoustic Analysis of Voice." Journal of Voice 25(1): 15-20. http://dx.doi.org/10.1016/j.jvoice.2009.08.004.

Maheshwari, Sudhanshu. 2018. "Some Analog Filters of Reduced Complexity with Shelving and Multifunctional Characteristics." Journal of Circuits, Systems and Computers 27(10): 1-19.

Marciniak, Tomasz, Damian Cetnarowicz, Paweł Pawłowski, and Adam Dąbrowski. 2019. "Designing of Analog Filters for Digital Signal Processing Modules.” Przeglad Elektrotechniczny 95(10): 125-29.

Miki, Takahiro, and Pat Rakers. 2004. Proceedings of the Custom Integrated Circuits Conference Analog Filters.

Mondal, Imon, and Nagendra Krishnapura. 2018. "Expansion and Compression of Analog Pulses by Bandwidth Scaling of ContinuousTime Filters." IEEE Transactions on Circuits and Systems I: Regular Papers 65(9): 2703-14.

Moseiko, N. I. et al. 2020. "An Analog-to-Digital Converter and Intelligent Controller for Use in a DAQ System Processing PMT Signals from Very High Energy Astrophysics Experiments." Nuclear Instruments and Methods in Physics Research, Section A: Accelerators, Spectrometers, Detectors and Associated Equipment 952(October 2018): 161755. https://doi.org/10.1016/j.nima.2018.12.070.

Okoniewski, Piotr, and Jacek Piskorowski. 2019. "Short Transient Parameter-Varying IIR Filter Based on Analog Oscillatory System." Applied Sciences (Switzerland) 9(10).

Raz, Zohar, Strategic Marketing, and David E Borth. 1986. "Group Semiconductor."

Rezaei, Nasser, and Abolfazl Salehi. 2006. "An Introduction to Speech Sciences (Acoustic Analysis of Speech).” Iranian Rehabilitation Journal 4(4): 5-14. http://irj.uswr.ac.ir/files/site1/user_files_055690/admin-A-10-1-3-3c7ebda.pdf.

Siegert, Ingo et al. 2014. "Investigation of Speaker Group-Dependent Modelling for Recognition of Affective States from Speech." Cognitive Computation 6(4): 892-913.

Thede, Les. 2005. "Practical Analog and Digital Filter Design Artech House , Inc ."

Vural, Revna Acar, Tulay Yildirim, Tevfik Kadioglu, and Aysen Basargan. 2012. "Performance Evaluation of Evolutionary Algorithms for Optimal Filter Design." IEEE Transactions on Evolutionary Computation 16(1): 135-47.

Wanhammar, Lars, and Lars Wanhammar. 2009. "Introduction to Analog Filters.” Analog Filters Using MATLAB: 1-26. 